\title{
On Theoretical Principles of Managing the Processes of Musical Communication in Society
}

\author{
Alexander Yakoupov \\ Russian State Specialized Arts Academy \\ Moscow, Russia \\ E-mail: rgsai@mail.ru
}

\begin{abstract}
The author considers the theory of musical communication management in contemporary society and its most relevant principles. The author focuses on the theoretical principles of multi-factor differentiation of the listening audience and purposeful programming. The theories of prominent musical sociologists such as Sokhor, Zuckerman, and others are presented.
\end{abstract}

Keywords-musical communication; listening audience; purposeful sociocultural; programming; art; culture

\section{INTRODUCTION}

In this article, using the attempted theoretical analysis of the essence, the means and channels of the diverse processes of the social musical communication, and of the certain problems of managing that communication, we would address the acute practical issues - we would try to lay the theoretical foundation for the ways and means of optimising the musical communicative processes, the ways and means aimed at increasing the socio-cultural role of the musical art. We suggest here a number of principles that we believe to be fundamental, the principles that could be of use in organising the musical life in the present-day society.

First of all, bearing in mind the extreme complexity of finding the deeper aesthetic meanings of music, the meanings that are closely related to the necessity of encoding and decoding the transmitted information, the meanings that depend on a vast number of factors, both objective and subjective, - bearing all that in mind we would try to focus upon a conceptual principle that we term as the principle of the multi-factor differentiation of the listening audience.

Then, taking into consideration this initial principle, we would discuss the other aspects of the emerging theory of managing the social musical communication - the principles of purposeful programming, theoretical forecasting and perspective planning.

The closing part of the article is dedicated to some possible ways of realising those principles, ways aimed at attaining a certain level in the management and administration of the processes of the social musical communication. Special attention is given to the influence that the current social and economic reform in Russia has upon the emergence and development of the marketing and management techniques in the social life of the musical art.

\section{The PRINCIPLE OF THE MULTi-FACTOR DIFFERENTIATION OF THE LISTENING AUDIENCE}

\section{A. On Criteria of Differentiation of the Listening Audience}

Today the sociologists believe that one of the basic factors of the social projecting and forecasting in the aesthetic culture sphere is contained in finding the true criteria according to which the actual tastes of the consumers of the products of that culture - the listeners, the readers, the viewers (see, for instance, 7) - could be differentiated. Thus the basis for the differentiating approach towards managing the social processes of musical communication should be related to the actual human readiness to fully perceive the musical piece, in the actually perceived tonal form of which quite diverse meanings are encoded. And the true aesthetic pleasure cannot be achieved unless the proper understanding and emotional insight into the author's 'artistic discovery' (L. Mazel) is attained, unless some decision is made about the performer's interpretation concept and it is either accepted or rejected.

The obvious fact that in a wide social environment the phenomena related to perceiving serious music invariably repeat themselves leads to the possibility of forecasting and projecting the musical needs of a particular group of listeners. Thus the typification of the listening audience takes on special importance. It is called upon to reach the two basic objectives. First, it is developed in order to find some methodologically significant regularities of consuming serious music - it is important for elaborating the optimum approach to forming the musical preferences. Second, the typification is aimed at defining the most effective structure of the communicative chain - the structure that would permit the best organisational conditions/circumstances for perceiving the musical values to be created. Let us first touch upon the general requirements to that theoretical procedure.

It is well-known that while trying to somehow typify or classify a certain phenomenon one gets the opportunity of seeing both its constant and variable, changing aspects. Supporting the necessity of differentiating between the inner properties and the outward characteristics of the complex phenomena of reality many scientists and scholars stress the fact that the true scientific cognition is impossible without finding a way to reduce all the uniqueness to some recurring 
elements (or types). In reality, those more or less stable elements are always present in a phenomenon in some hidden or irregular form.

Thus, to bring forth the regularity of the studied subjects, one has to clear up its types. And several typologies might be constructed in the course of a thorough study of any given subject. Still every typology should be built upon some kind of a common basis, that is, any given multitude should be differentiated and grouped in accordance to the same selected property [see 1,2].

Among the Russian sociologists, V. S. Zuckerman has carried out considerable work in that respect. He has suggested a classification of the listening audience according to the 'intonational experience' criterion, that is, according to the degree to which a listener has mastered the musical language. Five types of the music listeners are singled out in that aspect [3, P. 36-370]. The author characterises them as follows:

- those who are completely disinterested in music;

- those possessing a limited intonational experience (those oriented towards the light, entertainment music);

- those possessing a greater intonational experience, that is still limited to the traditional intonational sphere (oriented towards the folk music);

- those possessing a considerably rich listening experience, but lacking musical education (they like both serious and light music);

- those possessing a great intonational experience and musical education (a high level of musical culture).

\section{B. The Sokhor's Typology of Auditorium}

A. N. Sokhor [4], in his turn, suggests a differentiation of listeners according to the quality of their perception: the ability for the focused or careless listening, the measure of integrity: the fullness (multi-layer character of musical perception) and the adequacy of understanding music, the depths of sympathising with it and understanding the message (grades from the elementary physiological reactions to catharsis), the ability to distinguish and adequately appreciate the true aesthetic values.

Sokhor distinguishes three basic spheres of music: the serious, the light and the folk music. Each of them includes the three types of listeners the highly cultured/developed (the 'connoisseur' or 'expert'); the listener of average culture ('an amateur', 'dilettante'); the listener of low development/culture ('layman').

Considering the essential qualities of each of the types the author notes, 'The highly developed listener is capable of focused perception, he can hear the integral whole of the musical piece, the perception is complex and sufficiently adequate, he is capable of attaining catharsis experiencing music, he can distinguish and appreciate everything new in music, including something original. The listener of average development does not always sufficiently focus his perception, his understanding of the piece can be fragmentary, incomplete and only partly adequate, in his experiencing of music he does not go beyond just receiving an emotional impression, compensatory emotions or aesthetic pleasure, he appreciates the traditional in music. The low cultured listener is characterised by the 'scattered' perception, lack of understanding for music, by the superficial (entertainment) and non-aesthetic emotions, he appreciates the banal in music' [4, P. 164 - 165]. Sokhor stresses that the typology should be taken into consideration while coming in touch with every of the three mentioned musical spheres - the serious, light and folk music.

A. N. Sokhor's classification is interesting to us, among other things, because he considers the typology he suggested as an instrument for disclosing the social factors that regulate the formation of the listening groups and define their 'interrelationship'. And although he does not attempt to check the effectiveness of this instrument, but only sets it forth as a part of a hypothesis, we would like to give it some attention.

Comparing the various previous classifications offered by other scholars, Sokhor criticises the inconsistency of those classifications that were based upon different characteristics and properties and the types under the same heading were often 'overlapping' or even completely interchangeable. To avoid a situation of this kind, Sokhor suggests that the different properties and characteristics should be differentiated into three groups [4, P. $161-164]$.

- The extra-musical characteristics (the sociodemographic, socio-psychological, the individual psychological characteristics).

- The general musical characteristics (the musical abilities, the level of their development, the stimuli, the spurs, the motives for coming in contact with music, etc).

- The characteristics of the quality of the musical perception.

The comparison between the gathered data of the typological structure of the listening masses with the sociodemographic structure of the public and the other characteristics of the listeners might help, according to Sokhor's hypothesis, 'to disclose the social factors that regulate the formation of the listening groups and determine their interrelationship' $[4, \text { P. 166] }]^{*}$.

Of course, it is only theoretically that any abstract typology may be used in any actual contact between the musician and the public. In practice, there is no way that the actual public at a given concert may be separated and differentiated according to the previously determined typological properties. At the same time, the effectiveness of the musical impact greatly depends upon the purpose that is

\footnotetext{
In this particular work and any of the subsequent work Mr Sokhor failed to exemplify this kind of comparison by the material of any actual sociological research. Thus, his hypothesis needs to be scientifically proven Still, from the viewpoint of applied musical sociology, this problem seems remarkably acute.
} 
set for the music - the purpose closely related to the psychological properties and characteristics. Could the process of musical communication be managed in this case? Needless to say, that there is no possibility to arrange everything so that the actual audience of a concert would a hundred per cent correspond to any given listener's type, at least because within one and the same type there might be considerable differences exactly in the quality of musical perception.

Still, from the organisational viewpoint, there seems to be an opportunity to create such conditions that might assist in the formation of the audience according to the chosen properties and characteristics. The long experience proves that the whole history of the concert life is based upon the infinite process of differentiation of audiences according to their preferences and upon the musicians' intention to satisfy the listeners' interests. This differentiated approach is mostly based upon the empirically discovered method of purposeful addressing a particular audience.

\section{Zuckerman's Methodology of Studying Musical Interests of Listeners}

Unlike Sokhor, V. S. Zuckerman, using the results of certain sociological research, succeeded in disclosing the basic factors that determine the formation of the musical interests of the particular social groups. In his book The Music and the Listener he elaborates the methods of the differentiated approach towards the study of the musical interests of the various categories of the public. He suggests that age and education are the major determinants that lay the foundation for the musical interests of the different categories of the public. Setting the age gradations, the sociologist utilised his own applied research results - the results that suggested to him that when a person attains a certain age threshold his musical tastes and requirements change perceptibly. He defined the turning points of the change, although stating their relative character, and suggested the following age scale: $16-20 ; 21-25 ; 26-35$; $36-45 ; 46-60$.

The gradations that Zuckerman suggested in relation to the education level was based upon the traditional criteria: 1) elementary education (and lower); 2) 5 - 7 (8) grades; 3) 9 10 (11) grades; 4) secondary education; 5) unfinished higher education; 6) higher technical education; 7) higher humanitarian education.

The results of the research conducted by the mentioned author justified that classification and it is used as a standard one in most of the sociological sources.

However, at the beginning of the 80s the present author had an idea of checking the possibility of using the suggested typology as an instrument of organising the listeners in concert. It was assumed that Zuckerman's ideas on differentiating the approach to the study of the listeners' musical interests may be used as a direction in forming the audience of a particular concert. Working on the assumption, the City of Magnitogorsk philharmonic society used the characteristics mentioned in the typology as the basis for arranging the season ticket distribution.
The experiment conducted in this manner enabled some observations that were related to the problem of a purposeful organisation of the audience, rather than to the analysis of the musical preferences. Thus, it has turned out that the audiences are more readily organised according to social status. The level of education, as it was proven in the experiment, had no particular significance for the actual organisational work. Still, the age differentiation remained quite important.

During the same concert season another attempt to check the stability of the disclosed regularities was made - this time at concerts organised outside the season ticket system. The results justified the previous observations. It is noteworthy, that the same regularity was discovered by M. Sushchenko. As early as at the end of the 70 s he noted that the manifestation of a certain attitude to music largely serves a person as a way of identifying himself with the 'significant others' through a direct expression of his musical preferences. Thus using the symbolic affiliation to a certain group as a way of such manifestation, music and musical preferences may often serve as the means of keeping social distance and expressing solidarity. Therefore, the musical preferences, and, possibly, the content of the perception itself are largely predetermined by the group standards and expectations $[1, \mathrm{P}$. $260-261]$.

The differences that were here disclosed may be explained by the different purposes in using the mentioned typology. So, it has turned out that the principle of the listeners' differentiation suggested by Zuckerman - the principle used for the sociological study of the public musical interests - that principle cannot be utilised, without appropriate change, as an organisational criterion. Therefore, there is a necessity to develop a universal typological structure that would include new determinants that would at once suit the purposes of studying the listeners' interests and at the same time would be acceptable as the directions in practically organising the listeners.

As the result of the long lasting approbation in the concert practice, we have formed within this particular study quite a clear typology of the kind. It implies a simultaneous differentiation of the listeners' groups according to both the age and the social status. According to the received practical data, it is the age and the social status that act as the basic determining factors for the organisation of a certain type of listeners at a group level, and it is the age and the social status that can serve as the explanation of the listeners' motivation in satisfying their musical requirements. We believe the structure of the listening audience to be as follows:

- the groups differentiated according to the age gradations developed by V. S. Zuckerman ;

- the groups differentiated according to the social situation, they include: the kindergarten children; the schoolchildren (junior, middle and senior grades); the

\footnotetext{
"We haven't singled out the kindergarten and school children into separate age groups for they are included into the groups classified according to social status.
} 
vocational and technical school students; the students of the technical and humanitarian colleges; the industrial and office workers, the intelligentsia, the technical and humanitarian specialists and professionals, the managers and businessmen, the retired people/pensioners.

Summing up the above it is necessary to stress that the mentioned structure is not fixed once and for all - it is constantly transformed due to the significant social change. Thus, until just recently the managers of various companies and organisations normally showed no intention to unite according to their 'expression of pastime preferences'. But the tendency has been growing every year.

Let us now consider the other principles of managing the socio-musical communication.

\section{THE PRINCIPLE OF PURPOSEFUL PROGRAMMING}

\section{A. The Purposeful Programming in the Sphere of Art and Its Main Criteria}

Programming in the sphere of culture and art is one of the most popular ideas of the last decade. Thus, defining the notion of 'programme' $\mathrm{O}$. I. Genisaretsky believes that, as a rule, a programme is a directive document whose essence consists in a complex of definite steps and measures related by their content and goals, their performers and the time when they should be taken, their scale and their possible results. He believes that the difference between the purposeful programmes and the social projects lies in the fact that the former are characterised by a complex, generalising and linking property and may contain a number of particular projects [5]. In this case, project management is presented as a part (a structural fragment) of the purposeful programme management. This is the opinion that N. B. Krylova supports. Enlarging upon the idea, she writes, '... the programme projecting, as a more complex organisational level, where the projects are combined into programmes and take on a wider social status - this kind of projecting should satisfy a complex system of criteria: on the one hand it should be simple, economical, complete, integral, on the other hand flexible, complex, open and wide' [6, P. $45-46]$.

Purposefulness is one of the basic requirements to modern programming. Thus, the real value of creating programmes for the development of the musical culture (in the aspect of this particular study) may be defined, on the one hand, by the orientation towards the necessary level of interaction of the subjects of the various spheres of the sociomusical communication (including the critical evaluation of that communication and its theoretical justification), and on the other hand - by the generation of the most complex processes of the musical communication, the processes predetermined by the interaction. In that case, the

\footnotetext{
${ }^{* *}$ So, if in 1991 in Magnitogorsk only 8 specialised concerts for the managers of different rank were organised, in 1992 the number of such concerts rose to 14 . And the tendency persisted through the subsequent years. Maybe, one can account for the fact by the inclusion of the businessmen into this particular group - the people who were thus trying to define their place in the culture of the changing society.
}

programme of musical culture (musical life) development of a given region or, say, city may serve as at once a theoretical and a practical instrument that assists the appropriate social institutions in finding their necessary purpose, it may also serve as the fundamental basis for developing the particular plans and methods of musical life management. We should stress here that the culture theorists E. A. Orlova, Y.N.Selezneva, N. B. Krylova and others also note the same universal character of the purpose programmes in the other spheres of their application [see 7;8;6].

Unfortunately, to date the musicology lacks special studies in the field of programming ${ }^{*}$. The existing vacuum is partly filled by the works of culture theorists who note, for instance, that the programmes related to culture, irrespective of its particular field, should be based upon the two principles: they should be characterised by the complex and systematic character. The complex character generally implies the wide coverage by the aesthetic education (normally related to the whole unity of various arts) of all the regions, the whole population in order to 'equalise the cultural level of the nation' $[9$, P. 38].

Maybe this point could be to a degree accepted in the other kinds of art, but it is definitely inadmissible in relation to music. In cinematography, painting, literature and other fields of aesthetic creativity the inner contradictions between the serious and the light genres may not be as pronounced as in music.

These contradictions are mirroring the most global contradiction between the two polar outlooks of the world the spiritual and the spiritless. Therefore the preference towards this or that genre of music may serve as an indicator of the condition of the person's inner world.

Definitely, one may argue that there are many spiritually developed and cultured people among the advocates and supporters of the light genres of music. There is an explanation for that. As a rule, such people's inner world is formed by the reflection generated in contact with some other subculture and its spiritual potential. The light entertainment music presents in this case a certain kind of a 'vent', occupies one of the places in the person's routine pastime and entertainment. We believe that this is the only way to account for the certain orientation of the spiritually developed people towards some genres of the light music.

Continuing the discussion of serious music and stressing its favourable influence upon a person's spiritual and emotional world and intellectual activity we would like to touch upon an important issue considered in one of the related works. Y. N. Bogatyreva considered the educational capabilities of the musical art. Her study was based upon the experiments conducted in Saint-Petersburg, the Baltic states and Hungary. Using the experiment data she proves that the children who study the serious music and go to concerts are

\footnotetext{
* Just recently within the sociological commission (headed by Y. V. Dukov) of the All-Russian musical society proposals were made concerning the organisation of theoretical and research work in order to create a programme for developing the concert activity in Russia under the new social and economic circumstances.
} 
usually better developed (the intellect, memory, emotions) and are more academically successful at school in comparison to their 'non-musical' friends. Still, this is most likely a two-way process: an inverse dependence is quite possible - the more developed children are consequently more attracted to music - From this viewpoint the work by Bogatyreva unfortunately fails to disclose to what degree and due to which factors the contact with serious music stimulates the development of the children's intellectual and other abilities.

We should note that it is the study of these particular aspects that is of paramount interest, since these are the studies that are essential to the programming aimed at the optimisation of the social processes of musical communication. In short, realising the principle of the complex approach characteristic of the general cultural tendencies in programming one should bear in mind the particular situation of the musical art.

In Magnitogorsk the influence of music upon the inner world and the academic excellence of children was also experimentally researched. Thus, at school 14 two analogous groups of same age children were considered. One of the groups had church music classes at the musical studio that the school had. After the nine years of schooling the 'musical' classes fared much better at the final exams. The children were emotional, pleasant to talk to, open and ready for dialogue and communication. The experiment was repeated for a number of successive years, invariably with the same impressively positive result. The children in the other groups under study who were mostly fond of entertainment music did not show themselves to the same advantage.

It is known that similar results were achieved elsewhere, particularly where the elements of The Complex Programme of Aesthetic Education developed in the Siberian region were tested - in school 168 (Novosibirsk), school 3 (Rubtsovsk), the Norilsk art lyceum [see 10]. The experiments proved that the a complex of factors has the deepest impact upon the children's emotional and intellectual world - the combination of musical knowledge, the organised and systematic perception of music and the independent productive (performing) activity (we have previously touched upon this particular issue).

That is why it is important to take into consideration the unique characteristics of the musical art while realising the complex principle common to all the general cultural tendencies in programming. Moreover, we believe that a very careful approach should be adopted towards the advocates of the pluralistic ideas in aesthetic education, particularly, when the education of children is implied. And supporting the theorists who oppose the unification of the aesthetic education (Y. N. Selezneva, E. A. Chamokova and others) in principle, we believe that one should still bear in mind the essential and value content of the various kinds and genres of art.

It has already been mentioned that there exists another major principle of programming - the system principle. The systematic problems have recently been among the most acute ones. A number of circumstances account for that. G. P. Shchedrivitsky singles out a number of factors in the present socio-cultural situation that account for the appearance of the system movement and the tendency for its spreading into the sphere of culture and art. The factors are contained in the deepening process of the science and profession differentiation, the existence of the narrowly specialised channels for the transmission of the subject culture that is divided into separate parts, etc.

The previous chapters have given considerable attention to the discussion of the systems characteristics of the social processes of musical communication. So, here we would only like to stress the growing role of the systematic approach towards management and organisational and administrative activities in the present-day society, and the fact that the purposeful programming serves as a pledge, a guarantee for the realisation of that approach.

Let us try to define a number of systems approach requirements to the mass musical education in relation to a modern industrial city. We believe the requirements to be as follows:

- the unity of the purposes and the directions of the activity;

- a consideration for all the factors of the social, cultural and industrial life;

- the joint planning, the functional co-ordination of all the 'blocks' of the musical culture;

- a wide coverage of the whole city population based upon the differentiation of all the social and age groups;

- the constant compromise and combination of the purely educational and moral factors in working with the public whose involvement into the actual musical activity is a necessary requirement;

- guaranteeing the continuity, the unbroken character of the process;

- constant control of all the results of the undertaken activity.

\section{B. The Technologies of Sociocultural Purposeful Programming}

The 'technological' problems of the purposeful programming in the sphere of music were quite thoroughly elaborated in the works by O.I.Genisaretsky and E. A. Orlova [cf. 5; 7]. They suggested a succession of the six stages of the organisational cycle of the programming activity. The stages are as follows:

- the planning and projecting stage (related to the determination of the actual or possible problems 'within the object');

- the regulating and projecting stage (related to the ideas of the perspective social objectives, their priorities); 
- the socio-projecting stage (developing recommendations based upon empirical research);

- the programming and planning stage (the development of the programmes and strategic plans);

- the realisation stage (the realisation of the projected proposals; the mobilisation of the material means; defining the realisation dates, the people and organisations involved in the realisation of the project and solving problems, etc);

- the controlling and correcting stage (the generalisation and analysis of the realisation results, its effectiveness, etc - aimed at correcting the programme in the course of its realisation).

The very technology of developing a project of sociocultural programmes includes:

- the programme and the complex of methods aimed at retrieval, processing and analysis of the information the analysis necessary for defining the problem situation that is characteristic of the programmed object;

- 'the technological map' (or a set of directions) that contains a description of all the stages of the retrieval of the information significant for the imitation modelling and creating analytical multi-factor models of the projected changes, the necessary operations and their stages, the activity modes (temporal, logistic, legal, etc) and their material support;

- the analysis of the direct and possible indirect results that the realisation of the projected decision may bring about;

- the check of the viability of the socio-cultural project - the check that includes the experimental approval of the project and its evaluation from the viewpoint of social effectiveness.

The cited complex of stages through which the development of the socio-cultural programmes development may be basically used in programming the appropriate activity, the musical life of a certain locality (a town, a district, an educational institution, etc). But the related activity also has certain specific aspects that need to be separately discussed.

Thus, a very important point becomes obvious - the cited programming technology leaves the practical professionals who are actually responsible for the realisation of the programme a very 'minor' executive role - the role that is predetermined and elaborated by the theorists (see, for instance, points 4,5 of the cited set of organisational cycle stages).

Such an underestimation is not accidental, nor is it just a minor particular circumstance. This kind of mistake is quite common in social projecting. Consequently, interesting and socially important programmes remain unrealised.
The practical experience of developing particular regional programmes proves that much more attention should be given to issues of involving the practical specialists, not only into the realisation of the programmes, but also into the procedures of the theoretical analysis of the related problems, into working out the programme strategy. That is why we believe that it makes sense to independently single out this kind of programming activity into a separate stage of the organisational cycle, as a correcting and mobilising stage that implies that the practical specialists are consulted about the major objectives and goals, the priorities according to which the problems should be solved in the course of the future programme realisation, that also implies the creation of a system to stimulate the activity of those who realise the programme.

We would also like to stress another important point. We believe that the theorists who worked out the socio-cultural development programmes failed to give proper consideration to the man himself, who is the major object to which the purposeful programming is directed, and who is at once the subject of this whole complicated activity.

We have to stress that when a particular person has no knowledge of the objectives and the aims of the programme, no understanding of the importance and the necessity of coming in contact with the real spiritual values, when this is the case the person turns just into a passive observer of everything that is going on. The efficiency of all those who create the programme and organise its realisation is then perceptibly decreased. That is why the aspect of the programming activity that deals with directing it towards a particular person also needs to be singled out independently. This component may be termed as the publicity stage of the programme creation, the stage that includes certain activity aimed at explaining the objects of the programme to the public, at defining its value priorities, at publicising the spiritual enrichment, the models of a more perfect lifestyle, etc.

Very important is the methodology of a purposeful influence at a group level - the influence exercised through the usage of the concert and philharmonic forms and some other related kinds of musical activity. Since the problem is not thoroughly considered in the related literature we would specify the basic methodological aspects essential to making the programming decisions.

\section{The Methodology of Programs of Sociocultural Development}

1) The programmes should contain a whole complex of diverse activities aimed at introducing the beginners to the world of real musical culture. These activities should be conducted very carefully and elaborately, both from the organisational, and the content point of view. The environment in which the concert is arranged is very important, it should be adequate to the content of the music performed. Any speech addressed to the listeners before the concert is vitally important. 
2) One of the major problem situations at the first stage of the contact with music usually consists in the possible (in a vast majority of cases, actual) diversity of preferences manifest within the same social group (say, a part of the group is basically oriented towards the entertainment genres, the other - towards the serious, academic genres). The programming decision must include the means of inner differentiation of listeners within the group and appropriate methods of working with each of the respective subdivisions.

3) The purposeful programming based on the systematic approach in working with the social groups is especially effective when certain tactical techniques are put to proper use. Thus, in each group, it is worthwhile to single out those music lovers who exhibit most psychological readiness for the contact with the musical values and who possess at least some knowledge of the great spiritual value of art. Singling them out as leaders, we might 'direct' the rest of the listeners towards the realisation of the same spiritual priorities. Therefore the programme should contain special measures and activities that would provide the listeners with a special communicative channel that would enable the information interchange both within the same group, and between the groups ${ }^{*}$. Within a group, the communication might be arranged in a manner that would assist the beginner in understanding, and absorbing as model, the value potential of the musical pieces he/she heard. The inter-group communication, in its turn, should stimulate the search for the optimal means of understanding and absorbing music at the group level.

4) The programme should include various ways in which the past practical experience of the members of the group in perceiving music might be used (when the listening environment of a newly formed group is still very diverse). Here, the more experienced might both learn to appreciate the value of their experience and act as the leaders of the new social groups of listeners.

5) The purposeful programming takes on special importance when there is a pronounced 'shortage' of the listeners constantly oriented towards the high musical art. In these circumstances the programming should to a greater degree be based on the diversity of the kinds and forms of the listeners' musical activity, on the peculiar character of 'introducing the material' in each particular case.

Depending on the complexity and the scale of the problems to be solved, one might distinguish two types of the purposeful programming. The first type is the local programming that is aimed at a particular result in a certain situation, limited by the given temporal boundaries and the participating performers. Such programmes are usually developed with a view to a particular objective, activity or

\footnotetext{
* The issue has already been discussed when the different channels within which the information circulates during the processes of musical communication were analysed. We stress here that the data gleaned from the general and the detailed analysis of the musical communicative processes should be taken into consideration in the course of the purposeful programming in the sphere of musical life.
}

event. Like, for instance, a perspective programme of the mass musical celebrations or pageants in a city, the programme for developing the brass instrument performing, etc.

The second type includes the city programming of the musical art development, the programming conceived for a longer period in time, for a greater scale, a higher level of the interacting forces and aimed at involving every person in the city into the contact with the musical values. As a rule, this kind of programme cannot be realised without proper cooperation with the specialists from the other cultural fields, with the city administration, etc. The general object of such programmes is contained in stimulating the perspective development of the city musical culture.

\section{CONCLUSION}

The realisation of the programmes in the spheres of art and culture is greatly, if not wholly, dependent upon the public opinion. Therefore, the programmes should be very carefully developed: it is worthwhile to thoroughly elaborate the tactics of setting forth the programme initiatives, the tactics in which the two basic factors are very significant the succession of stages and providing the conditions for their realisation*".

The appropriate succession of the basic activity stages and creating the optimal conditions for coming through those stages is the pledge of the purposeful programming effectiveness. This goes for the programming in the sphere of music, too - the sphere whose specific character calls for a very sensitive approach to this kind of activity. For instance, one of the important optimising conditions for the adequate programming of the musical culture development may be contained in making up special initiative groups consisting of the professional musicians possessing a great feeling of social responsibility combined with a certain (analysed) experience of the related creative and aesthetic activity.

\section{REFERENCES}

[1] SUSHCHENKO, M. O. Upon Certain Problems of the Detailed Sociological Study of Music in the USSR // The Issues of the Sociology of Art. - M., 1979. - P. 240 - 272.

[2] SYSOYEVA, L. S. The Social and Activity Concept of Aesthetic Education: The Abstract of the Kandidat Research in Philosophy. Tomsk, 1990.

[3] ZUCKERMAN, V. S. The Music and the Listener. - M., 1972.

[4] SOKHOR, A. N. The Sociology and Musical Culture. - M., 1975.

[5] GENISARETSKY, O. I. Social Projecting as a Means of Active Cultural Policy // The Social Projecting in the Sphere of Culture. - M., 1986. - S. 29 - 43.

[6] KRYLOVA, N. B. The Problems of Aesthetic Education in the Aspects of the Social Projecting Ideas: An Overview / Informkultura, 'The Problems of Aesthetic Education' Series. M., 1987. - Issue I. - P. $45-46$.

[7] ORLOVA, E. A. The Problem-oriented Socio-cultural Projection: The Theory. The Method. The Evaluation // The Social Projecting and Purposeful Programming in the Sphere of Aesthetic Education:

* This issue is discussed in greater detail in another work by the present author $(298,73-74)$. 
An Overview / Informkultura, The 'Aesthetic Education' Series. - M., 1989. - Issue 1. - P. 12 - 39.

[8] KRYLOVA, N. B. Certain Theoretical Aspects of the Relationship Between Culture and Management // The Aesthetic Education of Today: Theory, Methodology, Practice. - M., 1990. - P. 25 - 27.

[9] The Aesthetic Education and Upbringing of the Young. - M., 1978.

[10] The Aesthetic Education of the Young: Problems and Prospects / Compiled and edited by M. M. Berlyanchik. - Novosibirsk, 1989. 